\title{
DIALÉCTICA Y ÉLENKHOS: HERENCIA SOCRÁTICA EN EL MÉTODO ARISTOTÉLICO
}

\author{
Claudia Seggiaro \\ Universidad de Buenos Aires \\ Consejo Nacional de Investigaciones Científicas y Tecnológicas \\ http://dx.doi.org/10.15304/ag.37.2.4088
}

\begin{abstract}
Resumen
En el presente trabajo, nos interesa establecer la posible influencia de Sócrates en la dialéctica aristotélica. Para ello, dividiremos el trabajo en tres secciones. En la primera, de forma muy escueta nos centraremos en la problemática de la reconstrucción aristotélica del pensamiento de Sócrates. En la segunda parte, analizaremos algunos aspectos del llamado método socrático. Finalmente, en la tercera sección, examinaremos qué aspectos de ese método podría haber heredado Aristóteles. Nuestra tesis es que la dialéctica aristotélica tiene reminiscencias socráticas que nos permiten hablar de una herencia socrática.
\end{abstract}

Palabras clave: Aristóteles, dialéctica, élenkhos, Sócrates.

\section{Abstract}

In the present work, we are interested in establishing the possible influence of Socrates in the Aristotelian dialectic. To do this, we will divide the work into three sections. In the first, we will focus very briefly on the problem of the Aristotelian reconstruction of Socrates' thinking. In the second part, we will analyze some aspects of the so-called Socratic method. Finally, in the third section, we will examine what aspects of this method Aristotle may have inherited. Our thesis is that the Aristotelian dialectic has Socratic reminiscences that allow us to speak of an inheritance Socratic.

Keywords: Aristotle, dialectics, elenkhos, Socrates.

Recibido: 19/05/2017. Aceptado: 20/12/2017. 


\section{Introducción}

Desde la aparición del texto de Owen, Tithénai tà phainómena (1961, pp. 83-103), la importancia de la dialéctica en Aristóteles ha sido objeto de innumerables trabajos. Las interpretaciones al respecto son múltiples y recorren todo el espectro de lecturas posibles, ya que van desde negar que la dialéctica tenga algún tipo de importancia epistémica a sostener que es la técnica que permite el conocimiento de los primeros principios. Sin embargo, y pese a tratarse de un tema altamente trabajado entre los estudiosos del corpus aristotélico, lo que se suele analizar son las características que dicha técnica tiene y su papel en relación con su concepción gnoseológica. El origen que la dialéctica tiene en Aristóteles ha sido estudiado en una escala significativamente menor. Por tal motivo, si bien, dada su complejidad, intentar abordar esta cuestión en todas y cada una de sus posibles aristas sería complicado, intentaremos comenzar a explorarla centrándonos en una de sus posibles influencias: Sócrates. Para ello, dividiremos el trabajo en tres secciones. En la primera, de forma muy escueta nos centraremos en la problemática de la reconstrucción aristotélica del pensamiento de Sócrates. En la segunda sección, analizaremos algunos aspectos del llamado método socrático. Con este análisis no pretendemos ofrecer un estudio erudito del tema, sino una reconstrucción sobre la base de los trabajos ya existentes. Finalmente, en la tercera parte, examinaremos qué aspectos de ese método podría haber heredado Aristóteles. Nuestra tesis es que es que la dialéctica aristotélica tiene algunas reminiscencias socráticas que nos permiten hablar de una herencia Socrática.

\section{La construcción aristotélica de la figura de Sócrates: fuentes y problemas}

Analizar la reconstrucción que Aristóteles hace del pensamiento de Sócrates es una tarea de gran complejidad. Las causas de esto no solo son que Sócrates no ha dejado plasmado su pensamiento por escrito, ${ }^{1}$ o que las opiniones de sus contemporáneos sobre él hayan sido dispares, ${ }^{2}$ sino también a que las referencias al pensamiento de Sócrates en el corpus aristotelico

\footnotetext{
${ }^{1}$ Para el abordaje de esta cuestión, véase Dorion (2011, pp 1-23).

2 Un ejemplo claro de esto es el contrapunto generado en la antigüedad entre dos imágenes de Sócrates: aquella perfilada por sus discípulos, quienes generaron una literatura apologética en torno a su figura, y aquella otra presentada por escritores y pensadores de la época, entre ellos Aristófanes, que lo consideraban un sofista (Las Nubes 90).
} 
son pocas y escuetas. ${ }^{3}$ A esto debemos sumarle dos dificultades adicionales, pues Aristóteles no solo realiza su reconstrucción del pensamiento de Sócrates en sus propios términos y teniendo como telón de fondo sus propios presupuestos, problemas e intereses, sino que la hace de segunda mano. En cuanto a la primera de estas dificultades, la tesis de Kahn (2001, p. 215), es que al citar a sus predecesores Aristóteles recrea un diálogo ficticio, fuera del tiempo, "una investigación que conduce a la formación de su propio sistema filosófico" (Kahn, 2001, p. 214). Según este autor, esta clave hermenéutica es usada para entender la manera en la que Aristóteles cita a los presocráticos, pero no es tenida en cuenta para analizar cómo retoma a Sócrates, cuando, en realidad, se debería proceder en ambos casos del mismo modo. Desde la perspectiva de Kahn, al reconstruir el pensamiento de Sócrates, Aristóteles trasmite un conjunto de especulaciones formuladas a partir de la lectura de los diálogos platónicos (Kahn, 2001, p. 215).

Si bien la tesis de Kahn es atendible, creemos que la manera en la cual Aristóteles distingue a Sócrates del personaje homónimo recreado por Platón muestra que su reconstrucción no pueden ser solo especulaciones basadas en los diálogos de este último. En este punto es esclarecedora la confrontación de Metafísica XIII 8, 1086b2-ss., y Acerca de la generación y corrupción II 9, 335b11 y ss. Mientras en el pasaje de la primera obra Aristóteles contrapone el universal socrático a la Idea platónica, mostrando sus diferencias, en el pasaje de la segunda obra sostiene que en el Fedón Sócrates habría identificado a las causas de las cosas con las Ideas. La lectura conjunta de ambos pasajes pone en evidencia que en este último caso solo puede ser una referencia al personaje platónico, en cuya boca es puesta la postulación de una teoría que no es propia, pues, caso contario, Aristóteles le estaría atribuyendo a Sócrates tesis contrarias entre sí.

En relación con la segunda dificultad, el acceso indirecto que Aristóteles tiene al pensamiento de Sócrates, la pregunta crucial es en base a qué fuentes reconstruye las concepciones atribuidas por la tradición filosófica a este último pensador. Desde la perspectiva de Kahn, en lo que respecta a la búsqueda por la definición y a la respuesta al tí esti, Aristóteles trae a colación el Sócrates platónico, ya que dicha cuestión aparece en diálogos como el Menón y el Eutifrón y es típicamente platónica, pero no socrática. Como

${ }^{3}$ Estos textos son: Metafísica I 6, 987b, Metafísica XIII 4, 1078b18-ss., Metafísica XIII 9, 1086b, Partes de los animales II 642a25-30, Refutaciones sofisticas 183b5-ss., Poética, Protréptico fragmento 8b, Sobre la nobleza fragmentos 2, 3b y 3c, Sobre los poetas 47b11, fragmento 7, Sobre la filosofía fragmentos 1-2, Sobre los pitagóricos fragmentos 3 a. 
consecuencia de esto, Kahn resta importancia al valor histórico del testimonio de Aristóteles. Desde su perspectiva (Kahn, 2001, pp. 208-209), nada cambia, si consideramos que Aristóteles también usa como fuente a Jenofonte, pues la reconstrucción de este último del pensamiento de Sócrates es tan dependiente de Platón como la de Aristóteles (Kahn, 2001, p. 209). Los textos de Jenofonte que se suelen utilizar para trazar un perfil de Sócrates, Recuerdos de Sócrates y la Apología, fueron escritos en su exilio, utilizando como fuente las obras de los discípulos de Sócrates que estuvieron junto a él hasta su muerte, tales como Antístenes, Euclides, Esquines y Platón. ${ }^{4}$

Según Giannantoni (1971, p. X), es evidente que el pensamiento de Sócrates era un problema para Aristóteles. Sin embargo, la información que tenía sobre el filósofo era más directa y atendible que aquella de la que disponemos nosotros. Quizá por esto Giannantoni señala que Aristóteles ha sido considero una de las fuentes fundamentales para reconstruir el pensamiento de Sócrates. Para este autor, la figura de Sócrates que se desprende de los testimonios del Estagirita era la de un lógico racionalista, inventor del concepto y de la definición de los universales (Giannantoni, 1971, p. X) - cuya fuente, aunque este autor no lo diga, es presumiblemente Platón.

En contra de esta tesis, Bataillard (2001, p. 224) sostiene que, de todas las concepciones atribuibles a Sócrates, Aristóteles solo se ocupa de una: la identificación entre la virtud y la ciencia, motivo por el cual su imagen de Sócrates, al igual que la de Aristófanes, es una caricatura arbitraria, producto de una reducción. Para este autor (Bataillard, 2001, p. 230), la reconstrucción aristotélica del pensamiento de Sócrates es incoherente y no dice nada del Sócrates histórico. Sócrates solo es el nombre para referirse a un conjunto de tesis reunidas bajo la equiparación entre virtud y ciencia y presentadas como la posición adversa a la propia.

Nuestra lectura se ubica en un punto intermedio entre la de este último autor y la de Giannantoni. Creemos que el Sócrates aristotélico es la construcción de un personaje basado en la peculiar lectura de los testimonios de otros pensadores que han plasmado su legado en sus escritos, pero no el Sócrates real cuyo pensamiento constituye un problema para los estudiosos. En este sentido, el Sócrates aristotélico no es menos complejo que el histórico debido a que se construye a partir de fuentes indirectas. No obstante, la reconstrucción de la figura de Sócrates ya sea en los diálogos platónicos, en

${ }^{4}$ Por este motivo, Kahn (2010, pp. 58 ss.) es sumamente crítico respecto de considerar a Jenofonte como fuente para la reconstrucción del pensamiento socrático. Para una reconstrucción de las críticas a Jenofonte como fuente, véase Brisson-Dorion (2004, pp. 137-140). 
los escritos aristotélicos o a través de las otras diferentes fuentes, nos remite a un personaje claramente identificable. ${ }^{5} \mathrm{El}$ hecho de poder reconocer detrás de esas múltiples reconstrucciones a ese personaje, ${ }^{6}$ al cual Aristoteles pretende retomar, hace viable analizar qué influencia pudo haber tenido su legado filosófico en el pensamiento del Estagirita.

\section{Bosquejos del élenkhos socrático}

Una de las obras en donde Aristóteles retoma el método de Sócrates es Sobre la filosofía:

De las inscripciones existentes en Delfos, "conócete a ti mismo" se consideraba la más divina y fue precisamente esta la que originó en Sócrates la perplejidad y esta forma de investigar, como ha dicho Aristóteles en sus obras platónicas (trad. Vallejo Campos). ${ }^{7}$

Debemos tener presente que este fragmento nos ha llegado a través de Plutarco en Obras morales y de costumbres XIV, más específicamente Contra Colotes, 1118c. El contexto en el cual Plutarco analiza la máxima délfica "conócete a ti mismo" y "cita" a Aristóteles es bastante particular, pues no está haciendo una exégesis de la problemática del conocimiento de sí, sino un análisis de las diferentes concepciones filosóficas acerca de lo que es, esto es, de lo real, y su naturaleza. En este contexto, en 1116e15, Plutarco habla de la visita a Delfos de Querefonte en la cual el oráculo le revela a este último que Sócrates era el hombre más sabio. Esta anécdota, conocida también a través de la Apología de Sócrates de Platón, es mencionada para introducir la siguiente cuestión: ¿Cómo las conversaciones de Sócrates podrían ser otra cosa que mera charlatanería, ya que este había confesado no saber nada, pero siempre estaba aprendiendo y en la búsqueda de la verdad? (1117d8-10).

${ }^{5}$ Pese a su lectura crítica, Kahn (2010, p. 35), habla de un "aire de familiaridad”. Según este autor, hay "una notable diversidad entre los retratos de Sócrates que ofrecen Esquines, Fedón y Jenofonte. Difieren entre sí tanto como lo hacen respecto de Platón, a pesar de que existe algo así como un aire de familia que une los cuatro retratos". Esto mismo es resaltado por Dorion (2011, pp. 7-9).

${ }^{6}$ Según Rodríguez Adrados (1992, pp. 29-52), la regla de Schleiermacher, según la cual las coincidencias entre el Sócrates platónico y el de Jenofonte deben ser tomadas como una fuente fidedigna para la reconstrucción del verdadero Sócrates, sirve, en realidad, para tener un común denominador, una imagen disminuida de su doctrina.

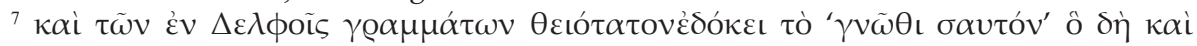

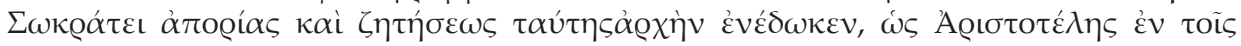

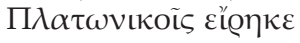


Lo relevante tanto del fragmento de Sobre la filosofía trasmitido por Plutarco como de su contexto es la relación que se establece entre la máxima délfica y el método socrático. En este sentido, son fundamentales los términos empleados para describir dicho método: aporía y zétesis. ${ }^{8}$ Desde la perspectiva aristotélica recogida por Plutarco, el método socrático está atravesado por la búsqueda, pero también por la problematización, esto es, por el estado de aporía que supone estar en conflicto respecto de algo que no se sabe. Este estado de aporía que implica la toma de conciencia de la propia ignorancia es la condición indispensable para iniciar el camino del conocimiento y, por lo tanto, de adquisición de la verdad. ${ }^{9}$ Tal proceder aparece descripto en Apología 29e-30a:

si alguno de vosotros discute y dice que se preocupa, no pienso dejarlo al momento y marcharme, sino que le voy a interrogar, a examinar y a refutar, y, si me parece que no ha adquirido la virtud y dice que sí, le reprocharé que tiene en menos lo digno de más y tiene en mucho lo que vale poco. Haré esto con el que me encuentre, joven o viejo, forastero o ciudadano, y más con los ciudadanos por cuanto más próximos estáis a mí por origen (trad. de Calonge). ${ }^{10}$

En esta obra, Platón no presenta a Sócrates como un maestro (didáskalos) y, por lo tanto, tampoco lo muestra como alguien que pretende enseñar una técnica o determinados contenidos (33 a-c). Sócrates es caracterizado como un hombre interesado en hablar y dialogar con el objeto de

${ }^{8}$ Como correctamente lo indica Politis (2006, p. 98), la aporía catártica está relacionada con el élenkhos socrático, ya que es el resultado directo de la refutación del interlocutor. Para este autor, la aporía socrática consiste en preguntar cómo pueden ser verdad dos tesis que en apariencia se contradicen. La aporía se presente de este modo como "un rompecabezas o problema particular cuya fuente es una contradicción aparente" (Politis, 2006, p. 98). Para Aubenque (2003, p.8), la aporía socrática no está en la pregunta, sino en la incapacidad de respóndela y el sentimiento de preocupación que esto genera. Desde la perspectiva de este autor, "Sócrates descubre el único poder legítimamente universal: el de la pregunta; el único arte al que ningún otro puede disputar la primacía: el de plantear cuestiones en el dialogo; dicho de otro modo, la dialéctica" (Aubenque, 2008, p. 233), entendida como el saber del no saber. Aguirre (2015, p. 33) señala que para Sócrates la aporía es "el lugar privilegiado desde el cual destruir falsas presunciones del conocimiento real esgrimido por sus interlocutores".

${ }_{9}^{9}$ Desde la perspectiva de Carpenter y Polansky (2002, p. 89), la refutación es la función más relevante del método socrático, pero no la única. Si bien todos sus otros propósitos son logrados por medio de la refutación, el élenkhos tiene como objetivos adicionales:1) investigar las pretensiones del interlocutor; 2) investigar la vida de los interlocutores; y 3) buscar amigos apropiados.

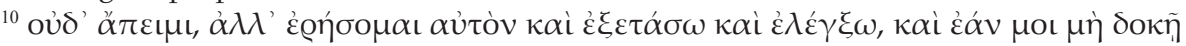

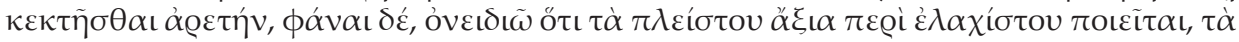

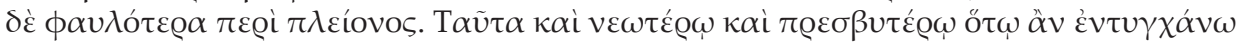

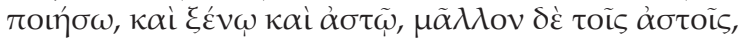


promover entre los hombres el cuidado de sí y, por ende, la persecución de las virtudes. ${ }^{11}$ Como consecuencia de esto, de él se dice que pretende hablar y ser escuchado por cualquiera, sin importar qué recursos económicos tenga. Claramente en este diálogo uno de los objetivos de Platón es diferenciar a Sócrates de los sofistas a los que suele describir como individuos que imparten sus enseñanzas de retórica a cambio de una remuneración. Por otra parte, parece ser un intento de responder a Aristófanes, quien presenta a Sócrates en tono burlesco y como un sofista más. ${ }^{12}$ Lo relevante de este pasaje y el motivo por lo cual lo traemos a colación es que, en él, Platón describe el proceder socrático en los mismos términos en que lo hizo Aristóteles en Sobre la filosofía. En ambos casos se recalca que el rasgo distintivo del método usado por Sócrates no es enseñar qué es la virtud o qué es lo bueno. Esto no implica que Sócrates desconozca aquello sobre lo cual pregunta, sino que el objetivo de la dialéctica socrática no es transmitir conocimientos. ${ }^{13}$ Dicho objetivo es refutar a los que creen ser sabios sin serlo, examinando "todas y cada una de sus pretensiones y los principios que guían su vida" (Gourinat, 2001, p. 157).14

Al describir el método implementado por Sócrates, Gourinat (2001, p. 145) señala que hay dos caracterizaciones de la dialéctica en los textos platónicos en los cuales Sócrates aparece como figura central. Bajo la primera, la dialéctica es un diálogo de preguntas y respuestas, llevado a cabo

${ }^{11}$ En este sentido, la tesis de Gourinat (2001, pp. 158- 159) es que Sócrates es un dialéctico y un moralista. Es un moralista, no porque tenga un sistema moral formulado, sino porque impulsa mediante la dialéctica a que los hombres se mejoren así mismos.

${ }^{12}$ Las Nubes 410-419.

13 Tarrant. H. (2002, pp. 61-77), describe el método de Sócrates como una amalgama de élenkhos y exétasis. Pese a esto considera que el término "élenkhos" no es el mejor para describir la metodología socrática, pues el élenkhos es una confrontación entre adversarios con la intención de alcanzar la refutación. Este autor considera que "exétasis" refleja mejor su método, ya que Sócrates se presenta a sí mismo como amigo y benefactor de aquellos que intenta examinar y porque dicho término está especialmente asociado con el examen de alguien. Esta tesis es objetada por Young (2002, pp. 78-87) con argumentos a nuestro juicio atendibles.

${ }^{14}$ Desde la perspectiva de Gourinat (2001, p. 157), en este sentido se debe entender las palabras de Aristóteles cuando declara que Sócrates preguntaba (Refutaciones sofísticas 183 b5 ss.), pero no respondía, pues declaraba no saber. Para Gourinat, no es que Sócrates no sea capaz de dar su opinión. No lo hacía, pues ello era su fin. Esto mismo ya era afirmado por Cicerón, cuando decía: "Sócrates usó mucho esta manera de conversar porque no quería ser él quien convenciera, sino que prefería extraer alguna conclusión a partir de lo que había admitido la persona con quien discutía, conclusión con la cual su interlocutor debía mostrarse necesariamente de acuerdo puesto que ya la había admitido" (Invención retórica 1,31 53. Trad. Nuñez). 
de la manera más sabia posible. ${ }^{15}$ Bajo la segunda caracterización, la dialéctica es la ciencia por la cual, en primer lugar, se ordena el conjunto de las impresiones y, en segundo lugar, se articulan las diferentes especificaciones de una idea para encontrar la forma buscada. Según Gourinat, estas caracterizaciones nunca aparecen en forma simultánea. ${ }^{16} \mathrm{El}$ hecho de que la segunda figure en textos tardíos es una posible muestra de que corresponde a la concepción platónica de la dialéctica y no a la socrática. La caracterización socrática de la dialéctica y, por lo tanto, del método socrático, sería la primera.

En Recuerdos de Sócrates, Jenofonte se refiere al método empleado por Sócrates en los siguientes términos:

Así es como decía Sócrates que los hombres se hacían mejores y más felices y más capaces de dialogar. Añadía que el nombre de dialéctica venía de ahí, de reunirse en común para reflexionar clasificando las cosas en sus géneros. ${ }^{17}$ Por ello había que intentar conseguir la máxima aptitud en esta disposición y preocuparse de ello al máximo, ya que por este procedimiento se forman los mejores hombres, los más aptos dirigentes y los más hábiles para el diálogo (4.5.12. Trad. Zaragoza). ${ }^{18}$

${ }^{15}$ Menón 75d, Crátilo 390, República 534b.

${ }^{16}$ Esto es la dialéctica como método de dividir y reunir la idea (véase Fedro 277b-c). Contrariamente a lo que sostiene Gourinat, Berti (2004, p. 412) afirma que el empleo de tal método no representa una ruptura con la concepción de la dialéctica descripta como método refutativo de los diálogos tempranos, ya que esta última aparece, según él, claramente reafirmada en el Sofista. En su período de vejez, Platón hace un uso constructivo de la refutación que le permite decidir qué ideas deben ser reunidas y cómo se debe hacer las divisiones, "de afirmar o negar según la verdad" (Berti, 2004, p. 413). La tesis de Berti supone que hay un desarrollo de la dialéctica platónica en la se conservan aquellos elementos del período socrático y, por lo tanto, podríamos decir, de la herencia socrática.

17 Diógenes caracteriza a Euclides como un pensador que desarrolló el mismo procedimiento de preguntas y respuestas que Sócrates. Es importante destacar que, como dice Gardella (2014, pp. 19-37), “aunque la dialéctica de Euclides deriva de la práctica del Sócrates histórico, se diferencia de la versión del élenkhos que Platón presenta en los primeros diálogos porque no pretende conocer lo que es ni persigue una mejora ética en el interlocutor. Por el contrario, sólo se limita a mostrar cómo el lenguaje, usualmente implementado como herramienta para adquirir el conocimiento de lo que es, constituye, en verdad, un dispositivo plagado de equívocos que obturan la posibilidad de acceder a lo real".

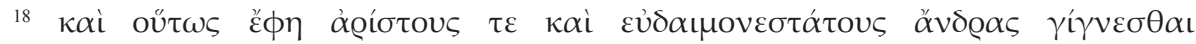

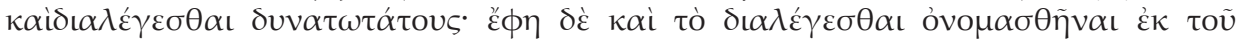

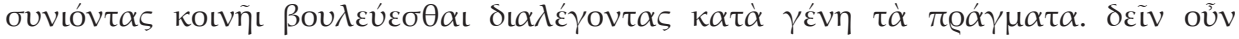

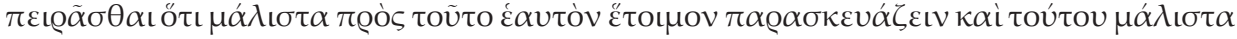

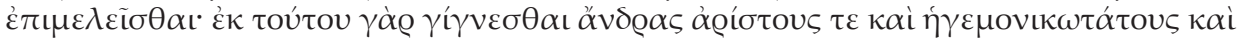

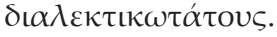


Para Jenofonte la dialéctica tal como era practicada por Sócrates implica el diálogo, pero también la búsqueda de lo que las cosas son, esto es, la indagación reflexiva ${ }^{19}$ mediante preguntar y respuestas, pero con el objeto de llegar a discernir la naturaleza del asunto de reflexión. ${ }^{20} \mathrm{Al}$ describir el método socrático, Jenofonte juega con el sentido de la voz media dialégesthai — dialogar-, y el sentido activo dialégein —clasificar. Combina ambos sentidos y los transforma en dos aspectos del mismo método. ${ }^{21} \mathrm{Al}$ hacer esto, según Gourinat (2001, p. 146), Jenofonte reúne en la caracterización de la dialéctica socrática los dos aspectos que en la obra platónica pertenecen a dos descripciones distintas de la dialéctica, a saber: la que llamamos propiamente socrática y la que aparece en los diálogos tardíos y que, por ende, tendría una impronta platónica.

Si bien compartimos la lectura de Gourinat en cuanto a la presencia de diferentes descripciones de la dialéctica en los diálogos platónicos, consideramos que en el pasaje arriba citado Jenofonte no está haciendo referencia a la misma noción de dialéctica descripta por Platón en escritos como, por ejemplo, Fedro 277b-c, sino a la búsqueda de la definición presentada por este mismo filósofo en sus diálogos tempranos o de transición, como el Eutifrón o Menón, razón por la cual Jenofonte no está reuniendo aspectos que

${ }^{19}$ Natali (2006, pp. 3-4) sostiene Jenofonte en su obra da cuenta de un aspecto positivo del procedimiento socrático. Según este autor, al igual que en algunas obras platónicas, se puede rastrear en los escritos de Jenofonte un intento de caracterizar a Sócrates como alguien dispuesto a aconsejar a sus amigos y preocupado por su bienestar (Recuerdos de Sócrates I. 4). Para este autor, Recuerdos de Sócrates es el principal testimonio de una dialéctica no-refutativa en Sócrates, una dialéctica que tiene el objetivo de llegar a determinaciones positivas, y definiciones del bien moral y de la virtud humana. Desde su perspectiva, "Élenkhos era una técnica preliminar para ser usada solamente con algunas personas que necesitaban ser convertidas" (Natali, 2006, p. 7). Si bien desde la parodia y el absurdo, Aristófanes describe el proceder socrático del siguiente modo: "pues vamos, tápate la cabeza, divide tu mente en pequeñas parcelas y estudia detenidamente el asunto, organizándolo y observándolo como es debido (Las nubes 740). Con Clay, D. (1994, p. 38), creemos que la representación de Sócrates realizada por Aristófanes es coherente con algunos rasgos que conocemos por medio de otros pensadores. En esta obra, se lo presenta usando su método dialógico de preguntas y respuestas y no largos discursos. Esta descripción del método es atestiguada también por Platón en Gorgias 449b.

20 "En efecto, Sócrates creía que quienes conocen lo que cada cosa es pueden también explicárselo a los otros, mientras que los que no conocen no sería sorprendente que se equivocaran ellos e hicieran equivocarse a los demás. Por ese motivo, nunca dejaba de examinar con sus seguidores lo que cada cosa es" (Recuerdos de Sócrates 461 . Trad. Zaragoza, levemente modificado).

${ }^{21}$ Para un análisis del juego entre dialégesthail dialégein, véase Gourinat (2001, p. 146). 
responden a nociones diferentes de dialéctica en Platón sino explorando el método socrático en el mismo sentido en que parece hacerlo este último.22 En este sentido es clave el siguiente pasaje de Menón:

En cuanto a mí, si el torpedo, estando él entorpecido, hace al mismo tiempo que los demás se entorpezcan, entonces le asemejo; y si no es así, no. En efecto, no es que no teniendo yo problemas, problematice sin embargo a los demás, sino que estando yo totalmente problematizado, también hago que lo estén los demás. Y a hora, "qué es la virtud" tampoco yo lo sé; pero tú en cambio tal vez sí lo sabías antes de ponerte en contacto conmigo, aunque en este momento te asemejes a quien no lo sabe. No obstante, quiero investigar contigo e indagar qué es ella (Menón 80c-d. trad. de Olivieri). ${ }^{23}$

En este diálogo, Menón interpela a Sócrates, pues desea saber si la virtud es enseñable o no. Frente a este planteo, Sócrates confiesa a Menón que no puede contestar su pregunta porque no sabe qué es la virtud, razón por la cual tampoco puede establecer si esta es enseñable. Paralelamente, Sócrates inicia un interrogatorio con el fin de poner en evidencia que Menón tampoco tiene este conocimiento, pese a estar convencido de lo contario. Es necesario que Menón sepa que no posee ese saber que daba por supuesto, pues esta es la única manera de poder empezar una indagación conjunta sobre la naturaleza de la virtud. Ser consciente de la ignorancia se presenta como el prerrequisito para poder comenzar una auténtica investigación sobre el tema a debatir. ${ }^{24}$ Ahora bien, esta búsqueda no es otra que la búsqueda de la definición, es decir, de su rasgo distintivo.

En el pasaje citado, Jenofonte habla del conocimiento de lo que las cosas son. Desde la perspectiva de Jenofonte solo los que tienen este conocimiento son capaces de dar una explicación satisfactoria de las cosas. Por lo tanto, el diálogo entre Sócrates y sus interlocutores tiene como objetivo descubrir qué son las cosas para luego poder dar cuenta de ellas. Jenofonte no dice que se trate de la búsqueda de la definición, pero la lectura del pasaje en su contexto parece indicar que la indagación llevada a cabo por

22 Rossetti (2011, p. 43) califica a los interrogatorios que forman parte del método socrático como un proceso estandarizado, ya que es fácilmente reconocible en las obras que pretenden retomarlos y que nos han llegado bajo la denominación "lógoi socráticos".

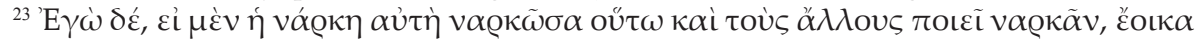

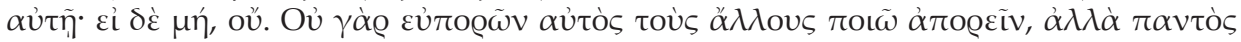

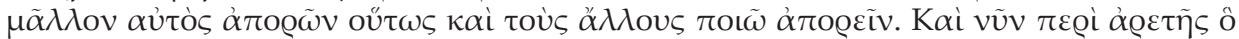

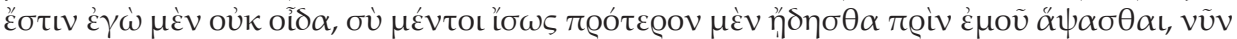

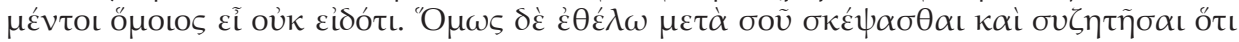

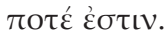

${ }^{24}$ Véase Robinson (1971, pp. 84-85). 
los interlocutores es la búsqueda del rasgo distintivo de las cosas, esto es, esencial, tal como ocurre en el Menón. Estos testimonios le permiten a Aristóteles sostener en Metafísica XIII 9, 1086b que el objetivo de Sócrates era la búsqueda de la definición, y que esta búsqueda era un rasgo distintivo de la dialéctica socrática, ya que "sin el universal no es posible alcanzar la ciencia” (XIII 9, 1086b5).

En relación con esta cuestión, retomando a Patzer, Giannantoni (2005, p. 322 $)^{25}$ sostiene que la pregunta por el tí estin constituye la primera fase de la dialéctica platónica. ${ }^{26}$ Lo propiamente socrático es el Wesenfrage, es decir, esencialmente el preguntar. Este autor llama la atención sobre el hecho de que en algunas obras tempranas de Platón la pregunta por el tí estin no está presente. Tales obras serían la Apología, el Criton, el Ion y el Hipias Mayor. En estos diálogos el modus operandi parece ser la refutación, la búsqueda por entender el sentido que los interlocutores les dan a las palabras y, por lo tanto, el examen semántico (2005, p. 319). Para Giannantoni, la pregunta por el tí estin no es definitoria ni esencial en los diálogos socráticos (2005, p. 324). ${ }^{27}$ Esto implica que para Sócrates, a diferencia de Platón, la función esencial del lenguaje es comunicacional y no expresiva de lo real (1993, p. 579).

Si bien no disentimos completamente de esta interpretación, creemos que no es completamente aceptable. Esto se debe a que, tal como indica Gourinat (2001, p. 158), el principal objetivo de Sócrates era la indagación sobre los principios de la acción. Desde la perspectiva socrática atestiguada por Platón y Jenofonte en los pasajes citados, solo se puede justificar una acción cuando se es capaz de dar cuenta de los principios que presupone, lo cual implica poder dar la definición de los conceptos involucrados en esos principios: qué es lo bello, lo bueno, lo justo. Esto no invalida que el interés de Sócrates haya sido a su vez comunicacional, pero el papel comunicacional del interrogatorio responde este objetivo y es subsidiario de él.

El procedimiento empleado por Sócrates es descripto tanto por Platón como por Jenofonte:

${ }^{25}$ Para Aubenque (2003, p. 8) la dialéctica socrática era el arte de preguntar, no de responder. Según este autor, el método de Sócrates de interrogar es independiente de todo saber.

${ }^{26}$ Para la problemática de la prioridad de la definición en Sócrates, véase Benson (2011, pp. 179-200).

${ }^{27}$ No obstante, este autor (2001, p. 17) sostiene que para Sócrates existen criterios estables, gracias a los cuales podemos entendernos con los otros y encontrar un acuerdo en la discusión. Desde su perspectiva, es la existencia de esos criterios lo que permite establecer si la conversación está correctamente establecida y constituye el fin del diálogo. 


\begin{tabular}{|c|c|}
\hline Jenofonte Recuerdos de Sócrates IV 615 & Platón Gorgias 506a3-7 \\
\hline $\begin{array}{l}\text { Una vez reconducida así la discusión, la } \\
\text { verdad se evidenciaba entre los mismos que } \\
\text { la contradecían. Y cuando él mismo quería } \\
\text { precisar algún argumento, iba avanzando } \\
\text { entre los puntos de mayor acuerdo, } \\
\text { convencido de que en ello consistía } \\
\text { la seguridad del razonamiento (Trad. } \\
\text { Zaragoza). }{ }^{28}\end{array}$ & $\begin{array}{l}\text { Tampoco digo lo que digo sabiéndolo } \\
\text { cabalmente, sino que indago en común } \\
\text { con ustedes, de modo que si me resulta de } \\
\text { peso algo que diga quien me discute, yo } \\
\text { seré el primero en estar de acuerdo. Por } \\
\text { cierto, esto lo digo si es que les parece a } \\
\text { ustedes que hay que llevar a su término la } \\
\text { discusión. Pero si no quieren, dejémosla } \\
\text { ya mismo y marchémonos. (trad. Santa } \\
\text { Cruz). }{ }^{29}\end{array}$ \\
\hline
\end{tabular}

Tanto en el pasaje de la obra de Jenofonte como en el extracto del diálogo platónico se deja entrever que la dialéctica socrática es una búsqueda conjunta en la que se pretende llegar a un acuerdo. Este acuerdo consiste en alcanzar una definición de aquello acerca de lo cual se está dialogando, es decir, de dar cuenta del rasgo esencial del objeto. Esto se logra mediante un proceso de preguntas y respuestas, en el cual los interlocutores deben estar dispuestos a ser refutados, si eso permite alcanzar la verdad. Nos resta establecer qué elementos podría estar retomando Aristóteles de este modo de proceder, que la tradición filosófica atribuye a Sócrates.

\section{La herencia socrática en la dialéctica aristotélica}

El rol de la dialéctica en Aristoteles ha sido objeto de innumerables estudios y debates. No es nuestro interés en este trabajo centrarnos en el análisis de este importantísimo pero complejo tema. Si bien la lectura de la obra que conforma el corpus nos permite decir que hay un uso del método dialéctico con fines epistémicos, ${ }^{30}$ en esta instancia nos interesa analizar qué herencia socrática supone este método independientemente del alcance que queramos asignarle a su utilidad epistémica.

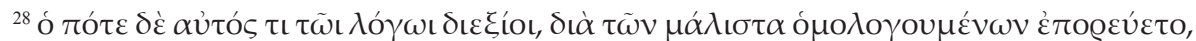

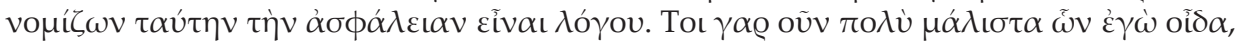

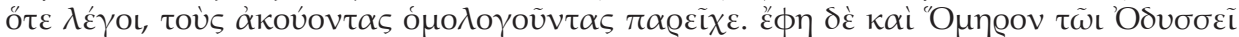

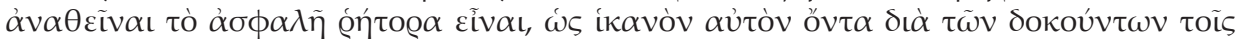

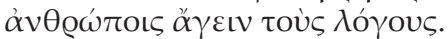

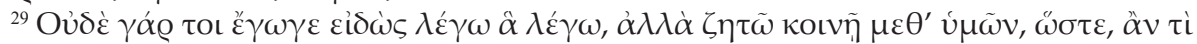

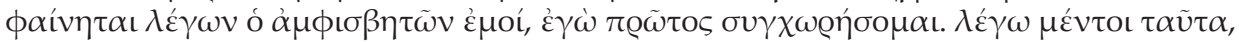

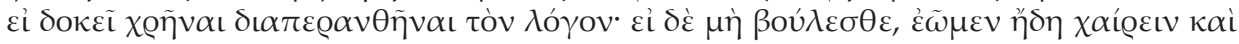

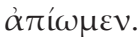

${ }^{30}$ Véase Tópicos I 1-2. Para un análisis más sucinto de esta cuestión véase Berti ( 2004: pp. 235-315); Bolton (1990, pp. 185-236.); Brunschwig (1990, pp. 237-262).; Di Camillo (2012, pp. 43-56); Rossitto, (2000, pp. 13-33). 
En este sentido, es relevante señalar que, en general, al realizar la indagación sobre un tema, Aristóteles comienza comentando las concepciones de sus predecesores. El modo en que los cita nos permiten concluir que su intención no es simplemente hacer un compendio de sus tesis sino instaurar una especie de diálogo con la tradición filosófica de la cual se siente parte.

\begin{tabular}{|c|c|}
\hline $\begin{array}{l}\text { Sobre la filosofía, fragmento } 13 \mathrm{~b}^{31} \text { Filón de } \\
\text { Alejandría Las alegorías de las leyes }\end{array}$ & Metafísica I 5, 987a2-7 \\
\hline $\begin{array}{l}\text { "los primeros pensadores indagaron } \\
\text { cómo llegamos a la noción de divino. } \\
\text { Posteriormente aquellos que parecen } \\
\text { filosofar mejor afirmaron que a partir del } \\
\text { mundo, de sus partes y de las potencias } \\
\text { que le son inherentes logramos aprehender } \\
\text { su causa" (trad. Vallejo Campos). }{ }^{32}\end{array}$ & $\begin{array}{l}\text { "De lo dicho y de los sabios convocados a } \\
\text { deliberación hasta este momento, hemos } \\
\text { recogido lo siguiente: los primeros filósofos } \\
\text { afirmaron que el principio es corpóreo } \\
\text { (ya que cuerpos son el agua, el fuego y } \\
\text { similares), y algunos dicen que es uno y } \\
\text { otros dicen que son varios los principios } \\
\text { corpóreos, si bien los unos y los otros los } \\
\text { sitúan en el ámbito específico de la materia" } \\
\text { (trad. de Calvo Martínez). }{ }^{33}\end{array}$ \\
\hline Física I 5, 188b26-30 & $\begin{array}{l}\text { Acerca de la corrupción y la generación } \\
315 \text { b16-19 }\end{array}$ \\
\hline $\begin{array}{l}\text { Hasta aquí la mayor parte de nuestros } \\
\text { predecesores de una u otra forma nos han } \\
\text { acompañado, como dijimos antes; pues } \\
\text { todos, como constreñidos por la verdad } \\
\text { misma, han dicho que los elementos, y } \\
\text { lo que ellos llaman "principios", son } \\
\text { contrarios, aunque no han dado ninguna } \\
\text { razón (trad. de Echandía). }{ }^{34}\end{array}$ & $\begin{array}{l}\text { Casi todos son del parecer de que la } \\
\text { generación y la alteración son diversas } \\
\text { una de otra, y que las cosas se generan y } \\
\text { corrompen por asociación y disociación } \\
\text { y se alteran al modificarse sus afecciones. } \\
\text { Por eso es preciso detenerse a considerar } \\
\text { estas cuestiones, pues contienen muchas y } \\
\text { razonables dificultades (trad. La Croce). }{ }^{35}\end{array}$ \\
\hline
\end{tabular}

${ }^{31}$ Para la numeración de los fragmentos de Sobre la Filosofía seguimos la edición de Ross.

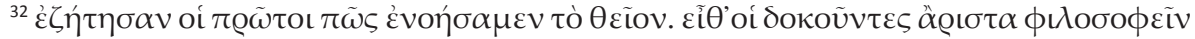

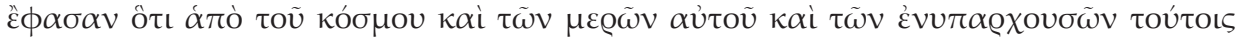

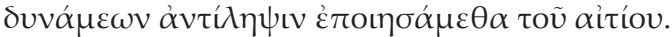

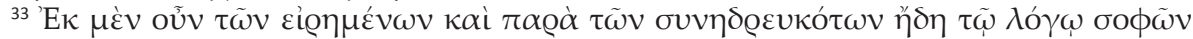

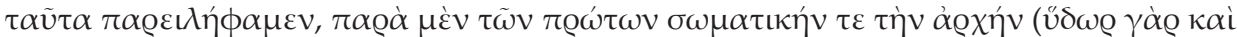

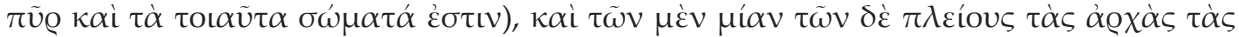

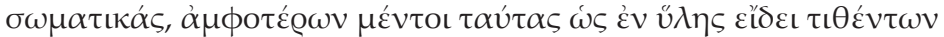

${ }^{34} \mu \varepsilon \dot{\chi} \chi \varrho \iota$

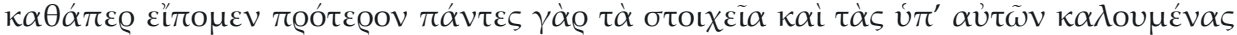

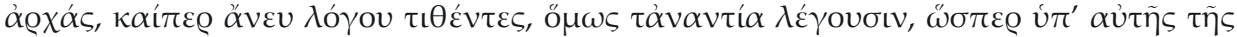
$\dot{\alpha} \lambda \eta \theta \varepsilon \dot{c} \alpha \varsigma \alpha \dot{\alpha} v \alpha \gamma \kappa \alpha \sigma \theta \dot{\varepsilon} v \tau \varepsilon \varsigma$.

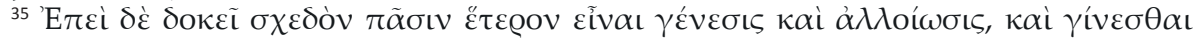

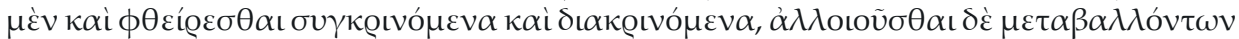

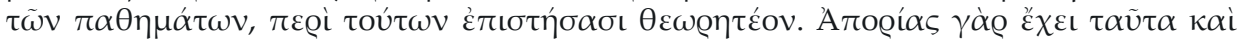

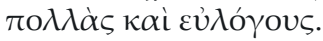


Si analizamos estos cuatro pasajes, podremos notar que en todos ellos Aristóteles procede de la misma manera: no solo trae a colación las opiniones de los predecesores, sino que los interpela, estableciendo sus supuestos, así como sus aciertos y desaciertos. En Metafísica I, se habla del tratamiento de las opiniones de los predecesores como un proceso de deliberación. Si bien es evidente que tal proceso deliberativo no existió, Aristóteles recrea un diálogo ficticio entre ellos como si realmente se estuviesen interpelando mutuamente y el Estagirita los estuviera cuestionando. ${ }^{36}$ El mismo modo de proceder está implícito en el pasaje de la Física en donde se habla de un acuerdo entre los pensadores. El uso de términos tales como sunedreúo (Metafísica I 5, 987a2-7) y sunakolouthéo (Física I 5, 188b26-30) es sugerente al respecto, porque muestra cómo Aristóteles genera un litigio ficticio en el cual se muestran acuerdos y disensos tal como sucedía en los diálogos de Sócrates con sus interlocutores. ${ }^{37}$

En todos los pasajes citados, Aristóteles retoma las concepciones de los predecesores como un punto de partida de su indagación y en todos estos textos reconoce el aporte de sus investigaciones en la búsqueda de la verdad y las problemáticas que han suscitado sus planteos. En Sobre la filosofía podemos rastrear una situación análoga: por un lado, reconoce la contribución de los que primero filosofaron, pero, por otro, admite las limitaciones que estos pensadores tuvieron, al ser los primeros que formularon los problemas y por no tener a nadie que les precediera en su investigación. ${ }^{38} \mathrm{Si}$ bien el Estagirita no relaciona en forma expresa el valor de dichas opiniones con el análisis que hace de ellas, el hecho de que comience su indagación por ese examen y que, al hacerlo, no se limite a sintetizar las tesis de sus predecesores es una muestra de que este modo de proceder forma parte de su búsqueda y no es solo un estudio preliminar que pretende dar un estado de la cuestión del tema. El motivo de esto aparece en Metafísica II 1, 993a 30-993b4, en donde Aristóteles manifiesta que, pese a que quienes le precedieron no han descubierto la verdad sobre la naturaleza de las cosas, han dicho algo sobre ella en forma oscura y difusa.

Tres de los pasajes citados, los de Metafísica I, Física I y Sobre la filosofía, forman parte de libros en los cuales se aborda la problemática de los

\footnotetext{
${ }^{36}$ Para abordar la relación entre dialéctica y diálogo, véase Gourinat (2002, pp. 463-495).

${ }^{37}$ Analíticos primeros I1, 24a25 Aristóteles dirá: "la dialéctica es la pregunta respecto de la contradicción".

${ }^{38}$ En Refutaciones sofísticas 184b 3-8, Aristóteles da un argumento análogo al que expone en Sobre la filosofía en el cual se expone la necesidad de valorar las opiniones de los predecesores.
} 
primeros principios. Es evidente que, al proceder del modo arriba descripto, Aristóteles no persigue el mismo objetivo que Sócrates, cuya pretensión es poner de manifiesto saberes aparentes. Para Aristóteles, los principios de las ciencias son indemostrables, ya que son autoevidentes y la precondición para el resto del conocimiento. En el caso del primer libro de la Metafísi$\mathrm{ca}^{39}$ Aristoteles no puede demostrar la existencia de las cuatro causas, pues está tratando sobre el objeto de la filosofía primera y, por lo tanto, de las primeras causas y principios (Analíticos segundos I 2, 72b19-30). El modo de proceder es establecer si entre las opiniones de los predecesores se puede rastrear los cuatro sentidos de causa por él propuestos en Física II 3 ( $\mathrm{Me}$ tafísica I 3, 983b1-6). A tales efectos, comienza a indagar las concepciones de los pensadores anteriores. El modo en que está escrito el libro genera la sensación de que son los mismos pensadores los que se objetan recíprocamente..$^{40} \mathrm{Al}$ hacer esto, Aristóteles procede dialécticamente, ${ }^{41}$ examinado las creencias de los pensadores que trae a colación, lo cual vimos en la sección anterior es un procedimiento que también era aplicado por Sócrates. ${ }^{42}$

En Física I también hay un uso de la dialéctica, pero no el descripto hasta aquí. En Física I 8, 191a 24-33, Aristoteles dirá:

Que sólo de esta manera se pueden resolver las dificultades de los antiguos, lo vamos a mostrar ahora. De los antiguos, los que primero filosofaron, al indagar sobre la verdad y la naturaleza de las cosas se extraviaron, como empujados hacia un camino equivocado por inexperiencia, y dijeron que ninguna cosa puede generarse o destruirse, puesto que lo generado tendría que llegar a ser o del ser o del no-ser, pero ambas alternativas son imposibles; porque de lo que es no puede llegar a ser, puesto que ya es, y de lo que no es nada puede llegar a ser, puesto que tendría que haber algo subyacente. Y así, extremando las consecuencias inmediatas, llegaron a afirmar que no existe la multiplicidad, sino sólo el Ser mismo (trad. de Echandía).

39 Para un análisis del uso de la dialéctica en Metafísica I, véase Rossitto (1993, pp. 372-379).

${ }^{40}$ Así, por ejemplo, en Metafísica I 3, 984b 8-11Aristóteles afirma: "Después de estos $\mathrm{y}<$ del descubrimiento $>$ de tales principios, puesto que eran insuficientes para generar la naturaleza de las cosas que son, forzados una vez más, como decíamos, por la verdad misma, buscaron el principio siguiente" (trad. Calvo Martínez)

${ }^{41}$ Tópicos I 2, 101a36-101b3: "En efecto, a partir de lo exclusivo de los principios internos al conocimiento en cuestión, es imposible decir nada sobre ellos mismos, puesto que los principios son primeros con respecto a todas las cosas, y por ello es necesario discurrir en torno a ellos a través de las cosas plausibles concernientes a cada uno de ellos. Ahora bien, esto es propio o exclusivo de la dialéctica: en efecto, al ser adecuada para examinar (cualquier cosa), abre camino a los principios de todos los métodos” (trad. Candel Sanmartín).

${ }^{42}$ Coincidimos con Fink (2012, pp. 1-26) en que para Aristóteles el sentido fundamental de la dialéctica es capturado por el procedimiento socrático de dar cuenta de las propias creencias en forma de preguntas y respuestas. 
Si bien no le corresponde a la física indagar sobre los primeros principios, Aristóteles considera que tiene interés filosófico y, por lo tanto, tiene sentido hacerlo debido a las consecuencias que de algunas posturas de sus antecesores se derivan. Partiendo del principio metodológico de que se debe comenzar por "lo más conocido para nosotros" para arribar a "lo más conocido en sí" (Física I 1), Aristóteles presenta las opiniones de los predecesores, ya que en relación con el tema a tratar constituyen aquello que, en principio, es lo más conocido para nosotros. Entre las opiniones que menciona están las de aquellos que sostienen múltiples principios y las de aquellos otros que solo creen en un único principio. En los primeros capítulos de este libro, Aristóteles examinará esta última opinión, pues quienes creen esto, los inmovilistas, niegan por ello la física y, toda ciencia en general. ${ }^{43}$ Puesto que todo principio implica por definición que exista algo respecto de lo cual es principio, quien acepta la existencia de un único principio debe conceder al menos la existencia de dos cosas: el principio y aquello que se produce a partir de ese principio. Si existiese un solo ser, este en rigor tampoco podría ser tratado como principio, razón por la cual quien sostiene tal tesis niega que la física tenga el status de ciencia. ${ }^{44}$ Sin embargo, el fracaso de quienes se ven forzados a concluir tales cosas es producto de su inexperiencia. No han podido ver que el ser se dice de muchas maneras (Física I 2, 185a21-32). El análisis de Aristóteles consistirá en sostener que el único resultado posible para quienes consideran seriamente la tesis de un único principio es la autorrefutación. El modus operandi, entonces no radica en presentar su tesis y presupuestos y confrontarlos con los de aquellos que postularon tal tesis, sino en un proceso refutativo en el cual se explicita la imposibilidad de sostener las tesis de quienes solo consideran la existencia de un único principio.

Desde la perspectiva aristotélica, el supuesto de estos pensadores es que la generación o es a partir de lo que es o es a partir de lo que no es. El primer caso es una situación absurda, pues lo que es ya sería. La segunda alternativa es una situación imposible porque nada puede llegar a ser de lo que no es. Esto los llevó a afirmar la existencia de un ser ingenerado e inmutable y, por lo tanto, de una sola naturaleza. Ahora bien, las consecuencias que de esto se derivan son autorrefutativas, pues, ya sea que acepten que lo que es

${ }^{43}$ Para esta cuestión véase, Boeri (2006, pp. 45-68); Rossi (2001, pp. 117-159).

${ }^{44}$ Esto se debe a que "creemos que sabemos cada cosa sin más, pero no del modo sofístico, accidental, cuando creemos conocer la causa por la que es la cosa, que es la causa de aquella cosa y que no cabe que sea de otra manera" (Analíticos segundos I 2, 71b8-10. trad. Candel Sanmartín). 
es uno en cuanto a la cantidad o en cuanto a la cualidad o en cuento a la esencia, caen de todos modos en situaciones inadmisibles para sí mismos, como por ejemplo admitir que lo mismo es ser hombre bueno y hombre malo (I 1, 185b22) o reconocer que lo uno es múltiple (I 1, 186a1-3).

Frente al posible cuestionamiento de la existencia los principios de la física, Aristóteles no puede proceder de forma demostrativa. Lo que puede hacer es tomar las concepciones de que quienes niegan esos principios y demostrar que, al hacerlo, se contradicen. Para esto, debe proponer un adversario, presentar su tesis y demostrar que de ella se desprende lo contrario de lo que sostiene como, por ejemplo, los múltiples sentidos del ser. Tal procedimiento es dialéctico, ${ }^{45}$ pero claramente es refutativo, ${ }^{46}$ uno de los rasgos distintivos de élenkhos socrático. ${ }^{47}$

${ }^{45}$ En Metafísica III 1 995a, 26-32, describe el método diaporemático diciendo: “detenerse minuciosamente en una aporía es útil para el que quiere encontrarle una salida adecuada. En efecto, la salida adecuada ulterior no es sino la solución de lo previamente aporético. Por lo demás, quien no conoce el nudo no es posible que lo desate. Pero la situación aporética de la mente pone de manifiesto lo problemático de la cosa. Y es que, en la medida en que se halla en una situación aporética, le ocurre lo mismo que a los que están atados: en ambos casos es imposible continuar adelante”. Tal como lo indica Aguirre (2015, p. 37), el libro III de la Metafísica tiene un carácter fundamentalmente metodológico y propedéutico", cuyo objetivo en su primera fase es la toma de conciencia de los problemas antes de "la búsqueda de una solución positiva” Aguirre (2001, p. 37). Véanse también los fragmentos 9 y 11-12 de Sobre la filosofía.

${ }^{46}$ En Metafísica IV 2, 1004b 25-26 dirá: "la dialéctica es tentativa y refutadora sobre aquellas cosas que la filosofía conoce realmente, y la sofistica, por su parte, aparenta ser sabiduría, pero no lo es". El término empleado para describir la dialéctica es peirastiké, adjetivo que le confiere a esta técnica el carácter de ser "crítica" o "examinadora". Esta manera de calificar a la dialéctica hace que este pasaje sea central a los fines de nuestro trabajo- demostrar la herencia socrática en la dialéctica aristotélica, pues el carácter refutativo y crítico es la característica central, por no decir esencial, del élenkhos socrático. Tal como lo indica Calvo Martínez (2007: 12) la dialéctica aristotélica, al igual que el método socrático, "somete a prueba y trata de refutar las tesis del interlocutor", basándose en opiniones preestablecidas (Refutaciones sofísticas 171b3-172b4). El pasaje comentado de la Física (I 8, 191a 24-33) puede ser visto como la puesta en marcha de este proceso dialéctico. En relación con Metafísica IV 2, 1004b 25-26, véase Berti (1997, pp. 379-396) y Vigo (2016, p. 1-24).

${ }^{47}$ Tal modo de proceder aparece también en Metafísica IV 3. Allí tampoco se puede hacer una prueba del principio de no contradicción porque, aun cuando esta fuera por el absurdo, se tendría que suponer el principio a demostrar. Lo que hace Aristóteles es construir un adversario radical que se opone a dicho principio. A este adversario se le pide que diga algo con sentido. Al hacer eso se intenta demostrar que, al negar el principio de contradicción, el adversario entra en contradicción consigo mismo, pues, al hacer lo que se le pide, debe presuponer el principio que niega. 
Este mismo procedimiento, aparece también en el pasaje citado de Acerca de la generación y corrupción 315b16-19, en donde Aristóteles, tras exponer la concepción de sus predecesores sobre las cuestiones que dan origen al nombre de la obra, cree oportuno detenerse en su análisis, pues encuentra en ellas serias dificultades. Si bien parte de una tesis sobre la cual encuentra cierto consenso, sostiene que hay que analizarla con detenimiento, pues su aceptación acarrea consecuencias inaceptables.

Este modus operandi implementado por Aristoteles en los pasajes citados aparece descripto en Refutaciones sofísticas 183a36-183b12:

Nos habíamos propuesto, pues, encontrar una capacidad de razonar acerca de aquello que se nos planteara entre las cosas que se dan como plausibles; en efecto, ésta es la tarea de la dialéctica propiamente tal y de la crítica. Pero, como quiera que, debido a su parentesco con la sofística, se la ha de enfocar de modo que no sólo se pueda poner a prueba (al adversario) de modo dialéctico, sino también hacer como si se conociera realmente (el tema), por eso nos impusimos como tarea de este estudio, no sólo lo dicho, a saber, ser capaces de envolver el argumento (del adversario), sino también que, al sostener nosotros mismos un argumento, sepamos defender la tesis a través de las (proposiciones) más plausibles dentro de cada tema. Y ya hemos dicho la causa de esto, ya que por esto mismo Sócrates preguntaba, pero no respondía: pues reconocía que no sabía. Se ha indicado ya en los (párrafos) anteriores respecto a cuántas cosas será esto así, y de dónde obtendremos estos recursos en abundancia, además de cómo hay que preguntar y ordenar toda la interrogación, y acerca de las respuestas y soluciones respecto a los razonamientos (del adversario) (trad. Candel Sanmartín).

La dialéctica es vista como un método basado en razonamientos cuyas premisas son éndoxa. ${ }^{48}$ Tal técnica supone un interlocutor, con el cual mantener una relación dialógica y discutir concepciones antitéticas. En consonancia con lo que Aristóteles señala en Tópicos I 1, 101a 25-35, la dialéctica no solo es un método que permite analizar las opiniones del interlocutor para evaluar la verdad o falsedad de sus enunciados, sino que nos proporciona los mecanismos para poder defender adecuadamente las tesis propias (Tópicos I 1, 100a 18-20). En las palabras de Aristóteles, podemos notar ciertas reminiscencias del siguiente pasaje del Gorgias, en el cual Sócrates manifiesta el objetivo de su interrogatorio y, por lo tanto, deja al descubierto algunos rasgos esenciales del élenkhos:

Sócrates: Te lo diré ahora. Esa persuasión producida por la retórica, de la que tú hablas, en qué consiste y acerca de qué clase de cosas trata, ten bien presente que no lo sé con claridad, pero sospecho que creo cuál es esa de la que hablas y acerca de qué cosas trata. Sin embargo, no por ello dejaré de preguntar en qué consiste, según dices, la persuasión producida por la retórica y acerca de qué cosas trata. Pero ¿con qué fin,

${ }^{48}$ Tópicos I 1. 
si yo lo sospecho, he de preguntarte, en lugar de decirlo yo mismo? No es por ti, sino por el argumento, para que progrese de modo tal que se nos vuelva perfectamente evidente aquello sobre lo que estamos hablando. Fíjate, pues, si te parece que estoy interrogándote de modo justo (Gorgias 453b1-c6. trad. Santa Cruz).

El interrogatorio de Sócrates, al igual que la dialéctica aristotélica, no pretende refutar solamente al adversario, sino descubrir la naturaleza del objeto de debate, en este caso, la retórica. En ambos casos, la discusión se plantea en términos de preguntas y respuestas y se pretende establecer las creencias que justifican la tesis del interrogado. Para Sócrates este era el preludio necesario para ser consciente de la propia ignorancia y de este modo iniciar la búsqueda de la verdad, ${ }^{49}$ una de las posibles funciones de la dialéctica, desde la perspectiva de Aristóteles. Para Aristóteles (Tópicos I 2), la dialéctica es una técnica que se puede utilizar: 1) como método refutatorio; 2) para las conversaciones, ya que, al conocer las opiniones de los otros, podremos hablar a partir de sus propios presupuestos y corregirlas en la medida que fuese necesario; 3) con fines filosóficos debido a que "pudiendo desarrollar una dificultad en ambos sentidos, discerniremos más fácilmente lo verdadero y lo falso en cada cosa. Pero es que además es útil para las cuestiones primordiales propias de cada conocimiento" (Tópicos I 2, 101a33-37. Trad. Candel Sanmartín). Podemos vislumbrar en esta descripción de las funciones de la dialéctica aristotélica algunos de los rasgos del método de Sócrates descriptos en el apartado anterior. Allí habíamos destacado el carácter refutativo del élenkhos (la primera función de la dialéctica aristotélica), cuyo fin era poner a prueba las creencias de los interlocutores (segunda función de la dialéctica aristotélica), para eventualmente dejar al descubierto su ignorancia. Paralelamente, también habíamos señalado que el objetivo de esto era la búsqueda conjunta de la verdad, lo cual implica un uso filosófico, tal como se nos indica en la tercera función de la dialéctica aristotélica. No obstante, debemos hacer la misma salvedad que ya realizamos más arriba: el objetivo de este uso filosófico no parece ser el mismo. En Aristóteles el uso filosófico de la dialéctica tiene como fundamento el hecho de que no puede haber conocimiento demostrativo de los primeros principios, por lo tanto, uno de los modos posibles de dar cuenta de ellos es mediante la dialéctica.

Las analogías existentes entre el método socrático y el aristotélico han llevado a algunos autores, entre ellos Bolton (1993, pp. 121-152; 2012, pp. 270-296), a sostener que Aristóteles no está inventando un método

${ }^{49}$ Véase Robinson (1971, pp. 78-93). 
sino haciendo una descripción del élenkhos socrático. Desde su perspectiva, Aristóteles está presentado el modo de proceder implementando por Sócrates y sus reglas en vista de una práctica correcta. Si bien creemos que afirmar esta tesis es decir demasiado, ya que la reconstrucción del método socrático es problemática y las referencias aristotélicas al pensamiento de Sócrates son escuetas, sobre la base de lo analizado en el apartado anterior y en este, sostenemos que la dialéctica aristotélica tiene una impronta del método empleado por Sócrates y en este sentido podemos hablar de una herencia socrática.

En contra de esta tesis, Dorion (2011, pp. 563-52) cree encontrar dos objeciones:1) Aristóteles se propone inventar un método, una tékhne, no solo una práctica, razón por la cual no podía contentarse con el élenkhos socrático. Para este autor, "no hay nada que nos permite creer que Aristóteles ha visto en Sócrates un practicante privilegiado de la dialéctica". 2) La dialéctica y la peirástica razonan habitualmente, según Aristóteles, a partir de lo que se cree habitualmente, esto es, de los éndoxa. Sin embargo, según Dorion, Sócrates desautoriza a sus interlocutores el uso de los éndoxa, razón por la cual la exigencia aristotélica de partir éndoxa no podría inspirarse en la práctica socrática de la dialéctica. ${ }^{50}$ En relación con la primera objeción, se puede decir que es un problema hablar de un método socrático, sin embargo, esto no quiere decir que Aristóteles no retome la práctica de la dialéctica socrática y la resignifique para sus propios fines. ${ }^{51}$ Es impor-

${ }^{50}$ Esta misma diferencia es marcada por Vlastos (1994, p. 13). Si bien para Aristóteles la base de la dialéctica son los éndoxa, no necesariamente todas las opiniones que dan origen al método dialéctico deben ser éndoxa. Tal es el caso de Metafísica IV 3, cuando Aristóteles pretende refutar a los que niegan el principio de no contradicción, o Física I 2, cuando aborda la tesis eléata de que solo hay una naturaleza. Por Tópicos I 11 sabemos que tales opiniones son paradojas, no obstante, dan lugar a procesos dialécticos (Véase Gourinat, 2002, pp. 474- 485). Por otra parte, que el método socrático no tenga como requisito expreso el uso de los éndoxa no quiere decir que no los emplee. El punto de partida del diálogo parece ser las opiniones del interlocutor o las que retoma del acervo cultural.

${ }^{51}$ Creemos que esto no es incompatible con las palabras de Aristóteles hacia el final de Refutaciones sofísticas (184b1 y ss.). Allí, Aristóteles señala que, si bien acerca de la retórica existen números escritos, no sucede lo mismo en relación con los procesos argumentativos, dentro de los cuales se encuentra la dialéctica, razón por la cual considera que su indagación sobre la cuestión constituye el comienzo de la investigación y, por lo tanto, que no tiene antecedentes. Creemos que a lo que apunta el Estagirita es que, antes de su examen, nadie ha desarrollado una sistematización satisfactoria acerca del razonamiento y el empleo de la dialéctica. Esto no quiere decir que no identifique en sus predecesores, entre ellos Sócrates, el empleo de ciertas prácticas, en las cuales cree ver prefigurados algunos de los procedimientos que sistematizará e implementara en las Refutaciones sofísticas y en otros escritos, como por ejemplo Tópicos. 
tante notar que tanto en la Poética (47b11) como en la obra fragmentaria Sobre los poetas (3a Diógenes Laercio, III 48) Aristóteles se refiere a los discursos socráticos como un conjunto de escritos que constituye un género literario cuya característica es que retoma cierta metodología que Sócrates implementó y que otros pensadores, como Platón, Euclides, Esquines y Antístenes, heredaron. Independientemente de que esto no sea una técnica, sino una práctica, esta puede ser vista como un proceder que muchos pensadores, entre ellos Aristóteles, desarrollaron en diferentes sentidos.

En cuanto a la segunda objeción, se debe señalar que, tal como lo indica Benson (2011, pp. 179-200), las premisas del élenkhos socráticos son creencias del interlocutor. Este autor sostiene que una de las marcas metodológicas del procedimiento implementado por Sócrates es que se parte de creencias que, si no son las del interlocutor, son tomadas del sentido común o de algún pensador reputado respecto del cual el interlocutor es el portavoz (Robinson, 1971, p. 92). Por tal motivo, si bien el método socrático es refutatorio, es refutatorio respeto de las creencias que los interlocutores tienen y cuya certeza no se cuestionan (Tarrant, 2002, p. 73). El método parte del compromiso doxástico que el interlocutor tiene en relación con las creencias que ha adoptado en el transcurso de su vida. Se les exige a los interlocutores que sean coherentes con ese sistema de creencias. Cuando esta coherencia no se da es porque el interlocutor no tiene un compromiso auténtico o firme con ellas y, por lo tanto, cae en contradicción. Si se acepta esto, se puede afirmar que la segunda objeción de Dorion no es de peso para refutar la tesis de una herencia socrática en el método aristotélico.

Sobre la base de lo argumentado hasta aquí, podemos concluir que no hay elementos que permitan establecer que la dialéctica aristotélica sea una adaptación del método socrático. Sin embargo, el recorrido por los diferentes pasajes de las obras de quienes retoman dicho método y el análisis de algunos de los extractos de los escritos aristotélicos nos permiten afirmar que la dialéctica aristotélica presenta elementos socráticos, que el Estagirita podría haber incorporado en su estancia en la Academia o a través de la lectura de los llamados "socráticos menores". Se trataría de una herencia mediada por quienes retomaron o reinterpretaron el modus operandi de Sócrates, tales como Platón, Jenofonte, Antístenes, Euclides, etc., pensadores que son citados en varias ocasiones por Aristóteles y que se consideran herederos del llamado método socrático. 


\section{Bibliografía}

Aguirre Santos, J., "Aristóteles: aporética como metodología. El caso de Metafísica B", en Revista Laguna n 9 (2001), pp. 37-52.

Aguirre Santos, J., Dialéctica y filosofía primera. Lectura de la Metafísica de Aristóteles, Zaragoza, Universidad de Zaragoza, 2015.

Aubenque, P., "Sens et fonction de l'aporie socratique", en Philosophie Antique, $\mathrm{n}^{\circ}$ 3: Enjeux de la dialectique (2003), pp. 5- 19.

Aubenque, P., El problema del ser en Aristóteles, trad. cast. de V. Peña, Madrid, Escolar y Mayor Editores, 2008 [1961].

Bataillard, M., "Socrates de Aristote: foundateur et fossoyeur de la morale", en Romeyer Dherbey, G. (Dir) et Gourinat, J. B. (ed), Socrate et les socratiques, Paris, Vrin, 2001, pp. 221-239.

Benson, H., "Socratic Method", en Donald R. Morrison. D. R. (ed), The Cambridge Companion to Socrates, Cambridge, Cambridge University Press, 2011, pp. 179-200.

Berti, E., "philosophie, dialectique et sophistique dans Métaphysique 2", en Revue Internationale de Philosophie 51 (1997), pp. 379-396.

Berti, E., Nuovi studi aristotelici, Brescia, Morcelliana, 2004.

Boeri, M., "Aristóteles contra Parménides: el problema del cambio y la posibilidad de una ciencia física", en Tópicos 2006, n 30 bis (2006), pp. 45-68.

Bolton, R., "The Epistemological Basis of Aristotelian Dialectic", en Devereux, D.- Pellegrin, P. (ed), Biologie, logique et métaphysique chez Aristote, Paris, Editions Centre National de la Recherche Scientifique, 1990, pp. 185-236.

Bolton, R., "Aristotle's Account of the Socratic Elenchus", en Oxford Studies in Ancient Philosophy 11 (1993), pp. 121-152.

Bolton, R., “The Aristotelian Elenchus”, en Fink J. L. (ed), The Development of Dialectic from Plato to Aristotle, Cambridge, Cambridge University Press, 2012, pp. 270- 296. https://doi.org/10.1017/CBO9780511997969.015

Brisson, L. - Dorion L. A., (2004), "Pour une relecture des écrits socratiques de Xénophon", en Les Études philosophiques, vol. 69, n 2 (2004), p. 137-140.

Brunschwig, J., "Remarques sur la communication de Robert Bolton, en Devereux, D. \& Pellegrin, P. (ed), Biologie, logique et métaphysique chez Aristote, Paris, Editions Centre National de la Recherche Scientifique, 1990, pp. 237-262. 
Calvo Martínez, T., Aristóteles, Metafísica, introducción, traducción y notas, Madrid, Gredos, 2007.

Candel Sanmartín, M., Aristóteles, Refutaciones Sofísticas, en Tratados de Lógica (Órganon), tomo I, introducción, traducción y notas, Madrid, Gredos, 1988.

Candel Sanmartín, M., Aristóteles, Tópicos, en Tratados de Lógica (Órganon), tomo II, introducción, traducción y notas, Madrid, Gredos, 1988.

Carpenter, M.-Polansky, R., "Variety of Socratics elenchi", en Scott, A. G. (ed.), Does Socrates have a method?: Rethinking the elenchus in Plato's Dialogue and Beyond, Pennsylvania, The Pennsylvania State University Press, 2002, pp. 80-100.

Crespo M. I,-Santa Cruz. M. I. Fedro, introducción, traducción y notas, Buenos Aires, Losada, 2007.

Clay, D., "The Origins of the Platonic Dialogue", en Vander Waerdt, P. (ed.), The Socratic Movement, Ithaca-Nueva York, Cornell University Press, 1994, pp. 23-47.

Di Camillo, S., Aristóteles historiador. El examen crítico de la teoría platónica de las Ideas, Buenos Aires, Facultad de Filosofía y Letras (UBA), 2012.

Dorion, L. A., "The Rise and Fall of the Socratic Problem", en Morisson, D. (ed) companion to Socrate, Cambridge, Cambridge University Press, 2011, pp 1-23.

Dorion, L. A., Aristote et l'élenkhos socratique, en Les Étudesphilosophiques, n 99 (2011), pp. 563-52.

Echandía, G., Aristóteles, Física, introducción, traducción y notas, Madrid, Gredos, 2007.

Fink, J. L., "Introdution", en Fink, J. L. (ed), The Development of Dialectic from Plato to Aristotle, Cambridge, Cambridge University Press, 2012, pp. 1-26.

https://doi.org/10.1017/CBO9780511997969 https://doi.org/10.1017/CBO9780511997969.001

Gardella, M., "Euclides de Mégara, filósofo socrático", en Agora, vol. 33, $n^{\circ} 2$ (2014), pp. 19-37.

Giannantoni, G., Socrate, Tutte le testimonianze: Da Aristofane e Senofonte ai Padri cristiani. Introduzione, traduzione e commento, Bari, Laterza, 1971. Giannantoni, G., Socrate nella Metafisica di Aristotele, en Rivista di Filosofia Neo-Scolastica, vol. 85, nº. $2 / 4$ (1993), pp. 566-584.

Giannantoni, G., "Les perspectives de la recherche sur Socrate", en Romeyer Dherbey, G. (Dir) et Gourinat, J. B. (ed), Socrate et les socratiques, Paris, Vrin, 2001, pp. 1-19. 
Giannantoni, G., Dialogo socratico e nascita della dialettica nella filosofia di Platone, Napoli, Biblopolis, 2005.

Gourinat, J. B., "Socrates Dialecticien ou moraliste?”, en Romeyer Dherbey, G. (Dir) et Gourinat, J. B., (ed), Socrate et les socratiques, Paris, Vrin, 2001. pp, 241-160.

Gourinat, J. B., "Diálogo y Dialéctica en los Tópicos y las Refutaciones sofísticas de Aristóteles”, en Anuario Filosófico, n 35 (2002), pp. 463495.

Kahn, C. H., La philosophie de Socrates selon Platon et Aristote, en Romeyer Dherbey, G. (Dir) et Gourinat, J. B. (ed), Socrate et les socratiques, Paris, Vrin, 2001, pp. 207- 220.

Kahn, C. H., Platón y el diálogo socrático. El uso filosófico de una forma literaria, trad, de Alejandro García Mayo, Madrid, Escolar Mayores y Editores, 2010 [1996].

La Croce, E., Aristóteles, Acerca de la corrupción y la generación, introducción, traducción y notas, Madrid, Gredos, 1987.

Macía Aparicio, L. M., Aristófanes, Comedias II. Las Nubes. Las Avispas, La paz, Los pájaros, introducción, traducción y notas, Madrid, Gredos, 2007.

Mársico, C., Filósofos socráticos. Testimonios y fragmentos I. megáricos y cirenaicos, introducción, traducción y notas, Buenos Aires, Losada, 2014.

Mársico, C., Filósofos socráticos. Testimonios y fragmentos II. Antístenes, Fedón, Esquines y Simon, introducción, traducción y notas, Buenos Aires, Losada, 2014.

Natali, C., "Socrates' Dialectic in Xenophon's Memorabilia”, en Judson, L.- Karasmanis, V. (ed), Remembering Socrates Philosophical Essays, Oxford, Oxford University Press, 2006, pp. 3-19.

Nuñez, S., Cicerón. Invención retórica, introducción, traducción y notas, Gredos, 1997.

Olivieri, F. J., Platón, Diálogos, vol. II, Menón, introducción, traducción y notas, Madrid, Gredos, 1987.

Owen, G. E. L., “Tithenai ta phainomena”, en Mansion, S. (ed), Aristote et les problèmes de méthode. Communications présentées au Symposium Aristotelicum tenu à Louvain du 24 aồt au 1er septembre 1961, Louvain, Publications Universitaire de Louvian, pp. 83-103.

Politis, V., "Aporía and Searching in the Early Plato", en Judson, L.Karasmanis, V. (ed), Remembering Socrates Philosophical Essays, Oxford, Oxford University Press, 2006, pp. 88-109.

Robinson, R., "Elenchus", en Bolton, R. (ed.), The Philosophy of Socrates, London, Palgrave Macmillan, pp. 78-93, 1971. 
https://doi.org/10.1007/978-1-349-86199-6 5

https://doi.org/10.1007/978-1-349-86199-6 4

Rodríguez Adrados, F., "La lengua de Sócrates y su filosofía”, en Méthexis, vol. 5 (1992), pp. 29-52.

Ross, W. D. (ed.), Aristotelis Dialogorum Fragmenta, Oxford: Clarendon Press, 1964.

Rossetti, L., "Socrate, questo sconosciuto", en Peitho/ Examina Antiqua vol.1, n¹ (2010), pp. 13-30.

Rossetti, L., Le dialogue socratique, Paris, Les Belles Lettres, 2011.

Rossi, G., "Algunas notas sobre la discusión con los eléatas en Física I de Aristóteles”, Tópicos, n 20 (2001), pp. 117-159.

Rossitto, C., "La Dialettica e il Suo Ruolo Nella Metafisica di Aristotele", en Rivista di Filosofia Neo-Scolastica, vol. 85, no. 2/4 (1993), pp. 370424.

Rossitto, C., Studi sulla dialettica in Aristotele, Napoli, Bibliopolis, 2000.

Santa Cruz, M. I., Gorgias, introducción, traducción y notas, Buenos Aires, Losada, 2013.

Tarrant, H., "Élenkhos and Exétasis: Capturing the Purpose of Socratic Interrogation", en Scott, A. G. (ed.), Does Socrates have a method?: rethinking the elenchus, Pennsylvania, The Pennsylvania State University Press, 2002, pp. 61-77.

Vallejo Campos, A., Aristóteles, Fragmentos, introducción, traducción y notas, Madrid, Gredos, 2005.

Vigo, A., "Filosofía y dialéctica en Aristóteles: un enfoque sinóptico", en Hypnos, $\mathrm{n}^{\circ} 36$ (2016), p. 1-24.

Vlastos, G., Socratic Studies, Cambridge, Cambridge University Press (1994).

Young, C. M., "Comments on Lesher, Ausland, and Tarrant", en Scott, A. G (ed.), Does Socrates have a method?: rethinking the elenchus, Pennsylvania, The Pennsylvania State University Press, 2002, pp. 78-87.

Zaragoza, J., Jenofonte, Recuerdos de Sócrates, introducción, traducción y notas, Madrid, Gredos, 2007. 